\title{
Implementasi API Payment Gateway Menggunakan Arsitektur Microservice
}

\author{
Erry Julio', Magdalena A. Ineke Pakereng ${ }^{2}$ \\ 1,2 Universitas Kristen Satya Wacana \\ Jl. Diponegoro No.52-60, Salatiga, Kec. Sidorejo, Kota Salatiga, Indonesia \\ e-mail: ${ }^{1}$ 672017022@student.uksw.edu, ${ }^{2}$ ineke.pakereng@uksw.edu
}

\begin{tabular}{llll}
\hline Informasi Artikel & Diterima: 02-06-2021 Direvisi: 30-06-2021 & Disetujui: 01-07-2021
\end{tabular}

\begin{abstract}
Abstrak
Untuk melakukan integrasi pembayaran online, PT. Emporia Digital Raya perlu membuat aplikasi Payment Gateway yang dapat meneruskan pembayaran ke bank tujuan. Arsitektur microservice dapat diterapkan untuk mengatasi masalah yang ada pada arsitektur monolithic dimana pengembangan aplikasi dilakukan dalam bentuk web service kecil yang saling berkomunikasi satu dengan yang lain. Dengan menggunakan konsep routing, payment gateway memiliki tanggung jawab seperti router dimana payment gateway berperan mencari rute ke bank mana data akan dikirimkan. Payment gateway akan memproses request dan membaca fields beneficiaryBankCode untuk menacari rute. Jika bank tujuan tidak ditemukan maka payment gateway akan menjalankan query dan mencari rute berdasarkan prioritas yang telah ditentukan oleh PT. Emporia Digital Raya.
\end{abstract}

Kata Kunci: Microservice, Payment Gateway, Bank

\begin{abstract}
To integrate online payments, PT. Emporia Digital Raya needs to create a Payment Gateway application that can initiate payments to destination banks. Architectural micro services can be applied to solve problems that exist in monolithic architectures where application development is carried out in the form of small web services that communicate with each other. By using the routing concept, payment gateways have responsibilities such as routers where the payment gateway participates in finding routes to the bank where the data will be sent. The payment gateway will process the request and read the beneficiaryBankCode field to find the route. If the destination bank is not found, the payment gateway will run a query and search for a route based on the priority set by PT. Emporia Digital Raya.
\end{abstract}

Keywords: Microservice, Payment Gateway, Bank

\section{Pendahuluan}

PT. Emporia Digital Raya atau biasa disebut EDR merupakan anak perusahaan PT. Anabatic Technologies, Tbk yang bergerak di bidang penyedia jasa E-Business dan ECommerce. Seiring berkembangnya aplikasi, EDR perlu mengembangkan sistem pembayaran dari tunai menjadi pembayaran online.

Untuk melakukan integrasi pembayaran online, EDR perlu membuat aplikasi Payment Gateway yang dapat meneruskan pembayaran ke bank tujuan. Ada beberapa bank yang bekerja sama dengan EDR yaitu PT Bank Negara Indonesia Tbk, PT Bank Mandiri Tbk, PT Bank Central Asia Tbk.

Application Programming Inteface (API) memungkinkan untuk aplikasi saling terintegrasi yang berbeda secara bersamaan. Representational state transfer (REST) adalah arsitektur API standar untuk layanan web yang memungkinkan meminta sistem untuk mengakses dan memanipulasi sumber daya web menggunakan protokol HTTP. REST menggunakan model client-server, dimana client mengirimkan permintaan HTTP (GET, POST, PUT, DELETE), bersama dengan URL. URL berisi parameter variabel di-encode yang menjelaskan objek untuk ditindaklanjuti dan server merespon dengan JavaScript Object Notation (JSON) yang valid (Beni Adi Pranata et al. 2018).

Arsitektur monolithic adalah suatu arsitektur dimana semua logika aplikasi berjalan pada satu server aplikasi. Proses pemeliharaan dan pembaruan aplikasi 
berukuran besar yang dibangun menggunakan arsitektur monolithic akan sulit dikarenakan kompleksitasnya (Mufrizal and Indarti 2019). Seiring berkembangnya aplikasi, arsitektur monolithic akan menjadi besar disisi lain arsitektur monolithic juga akan sulit dikembangkan (Setya Budi and Bachtiar 2018). Untuk mengurangi terjadinya kesalahan saat melakukan perbaikan atau penambahan fitur, EDR perlu membangun service yang dapat digunakan secara independen, diskalakan secara mandiri, dan memiliki satu tanggung jawab sesuai kebutuhan (Francesco et al. 2019).

Menurut laporan resmi Amazon Web Services (AWS), arsitektur monolithic memiliki berbagai masalah yaitu kompleks nya code dan sulit dalam pemeliharaan. Karena code berada pada satu server maka sulit untuk melakukan distribusi. Sedangkan arsitektur microservice memiliki manfaat seperti kecepatan pengembangan, kecepatan dalam penyebaran, code yang mudah untuk pelihara, dan pengoptimalan yang lebih baik (Amazon Web Services 2017).

Dalam aplikasi monolitik, setiap perubahan pada fungsionalitas tertentu dari aplikasi keseluruhan akan melibatkan kompilasi ulang dan, dalam beberapa kasus, pengujian ulang seluruh aplikasi sebelum diterapkan lagi. Namun, dalam kasus layanan mikro, hanya layanan yang relevan yang dimodifikasi dan diterapkan ulang karena sifat independen layanan memastikan bahwa perubahan di satu layanan tidak secara logis memengaruhi fungsionalitas layanan lain. Dalam aplikasi monolitik, Beberapa aplikasi monolitik dapat dibangun secara modular tetapi mungkin tidak memiliki modularitas semantik atau logis. Konstruksi modular mengacu pada bagaimana aplikasi dapat dibangun dari sejumlah besar komponen dan pustaka yang mungkin telah dipasok oleh vendor yang berbeda, dan beberapa komponen (misalnya, database) dapat didistribusikan ke seluruh jaringan (Chandramouli 2019).

Arsitektur microservice dapat diterapkan untuk mengatasi masalah yang ada pada arsitektur monolithic, aplikasi perlu dipecah menjadi beberapa bagian dimana pengembangan aplikasi dilakukan dalam bentuk web service kecil yang saling berkomunikasi satu dengan yang lain. Microservice menekankan manajemen mandiri dan ringan (Pahl and Jamshidi 2020).

Pada penelitian yang dilakukan (Chandra et al. 2020), Pembuatan aplikasi dengan arsitektur microservice dapat dilakukan dengan menentukan boundary context yang bertujuan untuk memisahkan service dari arsitektur monolitik menjadi microservice.

Gerbang API memainkan peran penting dalam arsitektur layanan mikro. API gateway, berfungsi sebagai gateway untuk setiap permintaan yang dimulai oleh aplikasi EDR, menyediakan fungsi publik seperti load balancing dan service blowing. Ini juga mengintegrasikan berbagai layanan mikro dan melindungi kompleksitas dan keragaman sistem, secara jelas menyederhanakan implementasi komunikasi antara aplikasi EDR dan layanan mikro (Zhao, Jing, and Jiang 2018).

Berdasarkan latar belakang yang telah dijelaskan, didapatkan simpulan bahwa diperlukannya arsitektur microservice guna mengatasi masalah kompleksitas sistem untuk memenuhi kebutuhan yang ada.

\section{Metode Penelitian}

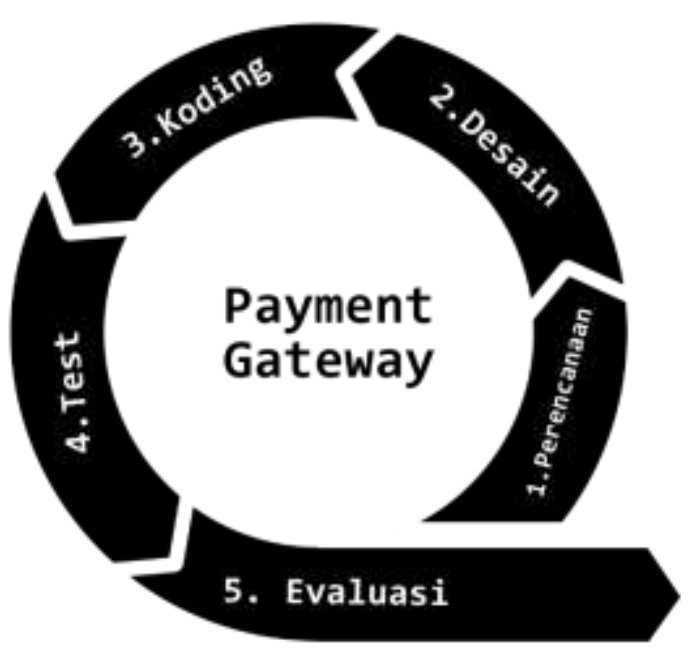

Gambar 1. Metode Agile

Pembuatan sistem pada penelitian ini dilakukan dengan membagi ruang lingkup menjadi satu set. Beberapa perencanaan, desain, implementasi, dan proyek penutupan proses manajemen dilakukan di setiap iterasi. Metode ini dikenal dengan istilah Agile (Jiménez, Afonso, and Fernandes 2020). Agile adalah metode pengembangan perangkat lunak jangka pendek yang memerlukan adaptasi cepat dari pengembang terhadap perubahan dalam bentuk apapun. Tahapan Agile dapat dilihat pada Gambar 1.

1. Perencanaan

Pada tahap perencanaan, dilakukan analisis terhadap spesifikasi proyek serta mengumpulkan informasi yang diperlukan untuk memenuhi kebutuhan pembayaran online. EDR membutuhkan sistem payment gateway untuk mengintegrasikan beberapa sistem bank yang 
berbeda sehingga proses komunikasi antar sistem dapat berjalan dengan aman dan lancar.

EDR membutuhkan payment gateway yang dapat melakukan routing. Routing adalah proses memilih jalur untuk lalu lintas di jaringan atau di antara atau di beberapa jaringan. Secara luas, perutean dilakukan di banyak jenis jaringan,antara subnet yang berbeda (Aljburi 2016).

Router adalah perangkat lunak dan perangkat keras yang bertanggung jawab untuk mengirimkan paket data antara dua subnet. Pada kasus ini, payment gateway memiliki tanggung jawab seperti router dimana payment gateway berperan mencari rute kemana data akan dikirimkan.

Tujuan data yang dikirimkan dapat diketahui dengan memproses request body yang dikirimkan oleh aplikasi EDR. Salah satu request body terdapat fields tujuan bank penerima yang berbentuk kode dari masing masing bank. Kode bank tersebut didefinisikan di database sehingga dari fields tersebut dapat disimpulkan service mana yang akan menerima data transaksi. Jika tujuan bank tidak ditemukan, maka service akan ditentukan berdasarkan prioritas yang di definisikan di database. Dengan hal tersebut maka EDR akan dikenakan biaya admin dikarenakan melakukan transfer atau transaksi ke berbeda bank.

Dalam pertukaran data diperlukan keamanan untuk mengurangi ancaman terhadap service. Menurut (Gunawan and Rahmatulloh 2019), JSON Web Token merupakan salah satu keamanan pada web service mampu mengatasi permasalahan interoperabilitas, mampu berinteraksi dengan aplikasi lain baik berbasis web, desktop maupun mobile. Jika konten data dirubah secara illegal, maka service akan memberikan respon bahwa token tersebut tidak valid. Dengan demikian penggunaan JSON Web Token Authentication dianggap aman. Otentikasi jenis ini juga telah dipakai juga oleh peneliti sebelumnya dalam membuat WEB API (Sahoo, Janghel, and Samanta 2017).

Service payment gateway merupakan aplikasi yang dibuat untuk kepentingan perusahaan internal.Untuk menghindari service ini digunakan oleh aplikasi yang tidak dikenal, diperlukan juga whitelist ip address untuk memblok aplikasi tidak dikenali yang ingin menggunakan service ini.

\section{Desain}

Dalam memahami aplikasi, developer akan dipermudah dengan adanya desain serta perancangan sistem. Perancangan ini merupakan pondasi awal sebelulm memasuki tahap koding dalam pembuatan aplikasi. Salah satu desain yang paling umum dan mudah dipahami yaitu flowchart atau diagram alir.

Diagram alir pada gambar 2 mendeskripsikan payment gateway dalam memproses data transaksi.

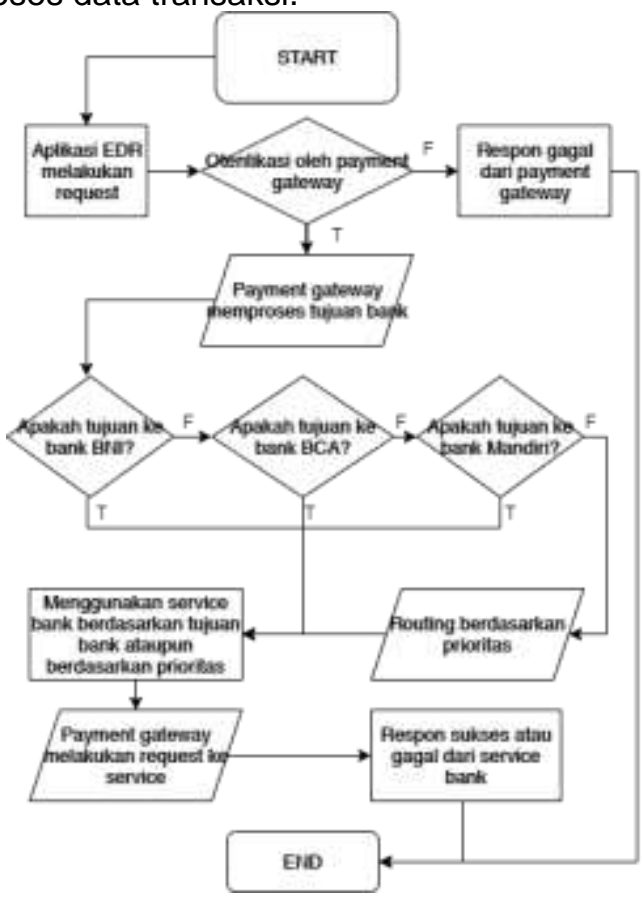

Gambar 2. Diagram Alir Payment Gateway

Standarisasi request perlu dilakukan dikarenakan setiap bank memiliki perbedaan spesifikasi dalam melakukan transaksi, maka dari itu konsep microservice diterapkan. Aplikasi akan dibagi menjadi beberapa bagian berdasarkan bank. Pembagian ini didasarkan pada perbedaan spesifikasi antar bank. Standarisasi dilakukan di setiap service yang akan terintegrasi di bank.

Setiap service akan dikenali dengan mengkonfigurasi ip address local dan port berbeda pada setiap service. Microservice bank akan mengidentifikasi service bank eksternal melalui bank kode yang telah didefinisikan di database. Pada kasus ini bank BNI telah disepakati oleh EDR memiliki prioritas utama yang berarti jika aplikasi EDR ingin melakukan transaksi diluar bank yang bekerja sama dengan EDR maka transaksi akan menggunakan bank BNI untuk diteruskan ke bank lain. Arsitektur microservice dapat dilihat pada gambar 3 . 


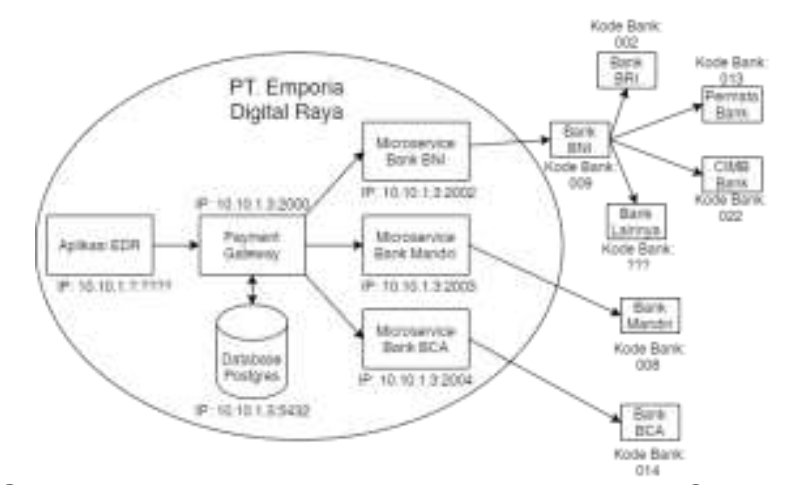

Gambar 3. Arsitektur Microservice Payment Gateway

Tabel 1. Tabel Mitra Di Database

\begin{tabular}{ccccc}
\hline $\begin{array}{c}\text { Bank } \\
\text { Code (PK) }\end{array}$ & Bank Name & $\begin{array}{c}\text { Priori } \\
\text { ty }\end{array}$ & Key Token & $\begin{array}{c}\text { Identifier Local } \\
\text { Service }\end{array}$ \\
\hline 009 & PT Bank Negara Indonesia & 1 & $\begin{array}{c}\text { e3c05ef5-8f9d-43d4- } \\
\text { bd3e-8c0fecd50715 }\end{array}$ & http://10.10.1.3:2002 \\
014 & PT Bank Central Asia Tbk & 2 & $\begin{array}{c}4923 e 7 a 5-1 e 20-4 a 0 d- \\
\text { a684-ec74ed00baa3 }\end{array}$ & http://10.10.1.3:2004 \\
008 & PT Bank Mandiri Tbk & 3 & $\begin{array}{c}8 \text { ceacc82-c957-417a- } \\
\text { 8311-6c5254431746 }\end{array}$ & http://10.10.1.3:2003 \\
\hline
\end{tabular}

Tabel 2. Tabel Routing Di Database

\begin{tabular}{|c|c|c|c|c|}
\hline $\begin{array}{l}\text { Bank } \\
\text { Code } \\
\text { (FK) }\end{array}$ & Usage & Method & Endpoint Local & Endpoint External \\
\hline 009 & TRANSFER & POST & /api/bni/transfer & $\begin{array}{c}\text { https://\{\{hostBNI\}\}/p2pl/payment/tran } \\
\text { sfer }\end{array}$ \\
\hline 009 & $\begin{array}{l}\text { TRANSFER } \\
\text { INTERBANK }\end{array}$ & POST & $\begin{array}{l}\text { /api/bni/transferlnte } \\
\text { rbank }\end{array}$ & $\begin{array}{c}\text { https: } / /\{\{\text { hostBNI }\}\} / p 2 p l / p a y m e n t / i n t e r \\
\text { bank }\end{array}$ \\
\hline 014 & TRANSFER & POST & /api/bca/transfer & $\begin{array}{c}\text { https://\{\{hostBCA\}\}/banking/corporate } \\
\text { s/transfers }\end{array}$ \\
\hline 008 & TRANSFER & POST & /api/mandiri/transfer & $\begin{array}{c}\text { https://\{\{hostMandiri\}\}/gateway/TbwP } \\
\text { ayment/1.0/doPayment }\end{array}$ \\
\hline
\end{tabular}

Tabel 3. Tabel Client Di Database

\begin{tabular}{cccc}
\hline $\begin{array}{c}\text { ID } \\
(\mathrm{PK})\end{array}$ & Service Name & Allowed IP & Key Token \\
\hline 1 & & & \\
2 & IKI PPOB & 139.99 .60 .117 & 09ec79db-a383-48c9-aee6-1ea516b64f50 \\
\hline
\end{tabular}

Semua service bank yang telah melakukan kerja sama harus di definisikan di database. Tabel 1 merupakan isi dari service bank yang bekerja sama dengan EDR. Kolom Bank Code merupakan primary key dan bersifat unik. Nama dari setiap bank di simpan di kolom Bank Name. Saat tujuan bank transaksi tidak ditemukan maka payment gateway akan melakukan routing berdasarkan prioritas. Key Token merupakan key yang digunakan untuk membuat otentikasi JWT. Kolom Identifier Local merupakan alamat host agar payment gateway dapat melakukan HTTP request ke microservice lainnya.
Setelah payment gateway melakukan routing dan meneruskan data dari aplikasi EDR ke microservice, selanjutnya microservice akan membaca Tabel 2 untuk melakukan request ke bank tujuan dengan membaca kolom Endpoint External. Setelah menerima response dari bank maka response tersebut akan dikembalikan ke payment gateway yang selanjutnya akan diteruskan kembali ke aplikasi EDR.

Tabel 3 merupakan definisi dari aplikasi EDR yang akan menggunakan payment gateway. Whitelist ip dilakukan dengan membaca kolom Allowed IP pada tabel 3. Sedangkan kolom Key Token digunakan 
untuk membuat otentikasi JWT oleh aplikasi EDR.

\section{Implementasi / Koding}

Implementasi menggunakan teknologi

NodeJS dengan framework ExpressJS. NodeJS merupakan runtime environment javascript yang digunakan untuk membuat server. Payment gateway akan membaca rute yang diakses oleh aplikasi EDR. Selanjutnya payment gateway akan memproses request dan membaca fields beneficiaryBankCode untuk mengetahui bank mana yang akan dituju.

Setelah mendapatkan kode bank, payment gateway akan menjalankan query berdasarkan kode bank untuk mencari bank tujuan. Jika bank tujuan tidak ditemukan maka payment gateway akan menjalankan query berdasarkan prioritas. Prioritas yang terkecil yang akan diutamakan untuk melakukan transfer. Sintaks dapat dilihat pada gambar 4 .

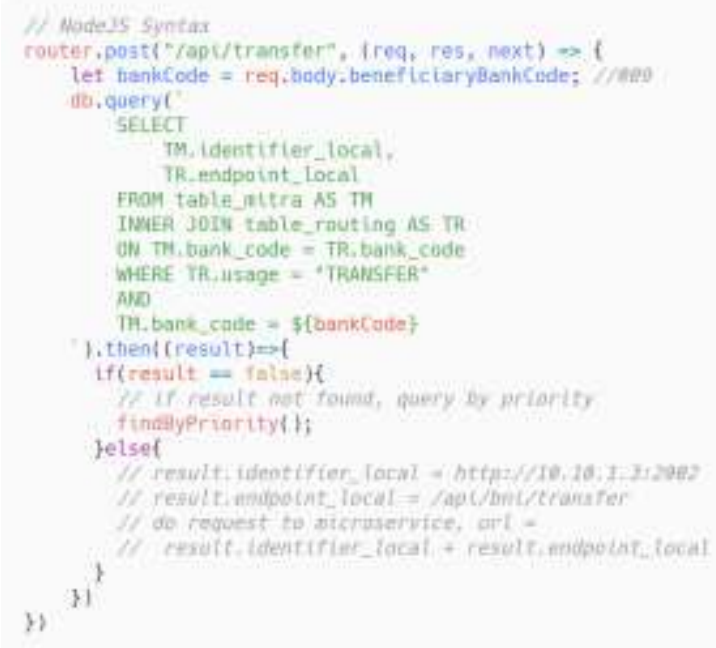

Gambar 4. Arsitektur Microservice Payment Gateway

\section{Testing}

Pengujian merupakan bagian penting dari setiap proses pengembangan perangkat lunak di mana perusahaan mencurahkan banyak waktu dan tenaga.

Berbagai jenis teknik pengujian seperti pengujian unit, pengujian cakupan, pengujian struktural, pengujian statistik, pengujian interaksi kombinatorial, pengujian penetrasi, pengujian rekayasa perangkat lunak berbasis pencarian, pengujian hierarki, pengujian bypass, pengujian kompatibilitas lintas browser, memanfaatkan pengujian data sesi pengguna telah disajikan oleh berbagai peneliti dalam konteks pengujian aplikasi web (Lakshmi and Mallika 2017).

Pengujian unit adalah metode pengujian perangkat lunak di mana setiap unit kumpulan source code satu atau lebih modul program komputer bersama dengan data kontrol terkait, prosedur penggunaan, dan prosedur operasi diuji untuk menentukan apakah cocok untuk digunakan.

Popularitas alat untuk analisis kualitas perangkat lunak telah meningkat selama bertahun - tahun. SonarQube adalah salah satu alat dan penyedia yang paling banyak digunakan (Saarimaki et al. 2019). SonarQube merupakan alat otomatis untuk menganalisis kode, mendeteksi bugs, kode yang tidak sesuai dan kerentanan terhadap keamanan. Jika SonarQube menemukan isu dalam kode maka akan menampilkan seperti gambar 5 .

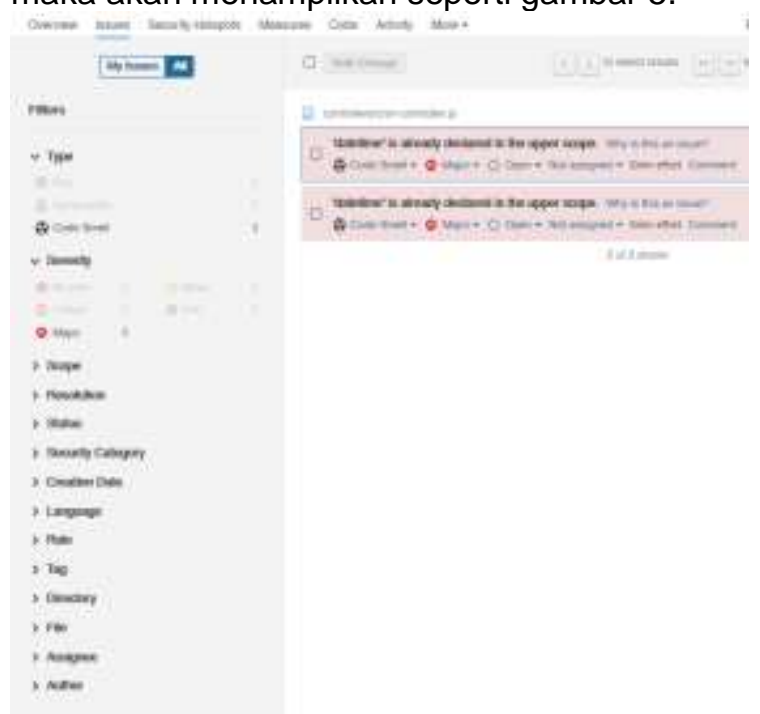

Gambar 5. Isu Kode Payment Gateway

5. Evaluasi

Setelah melakukan testing ada baiknya developer melakukan evaluasi dan perbaikan bugs jika ada. Pada hasil report SonarQube terhadap payment gateway, terdapat beberapa code smells. Dengan hal ini developer bertanggung jawab untuk memperbaiki bugs.

SonarQube juga memberikan rating A untuk maintainability. Selain itu, SonarQube memberikan saran untuk perbaikan kode. Hal ini berarti para developer tidak butuh banyak usaha ataupun waktu untuk mengatasi permasalahan code smells. Jika permasalahan sudah teratasi semua maka SonarQube akan memberikan report seperti gambar 6 . 


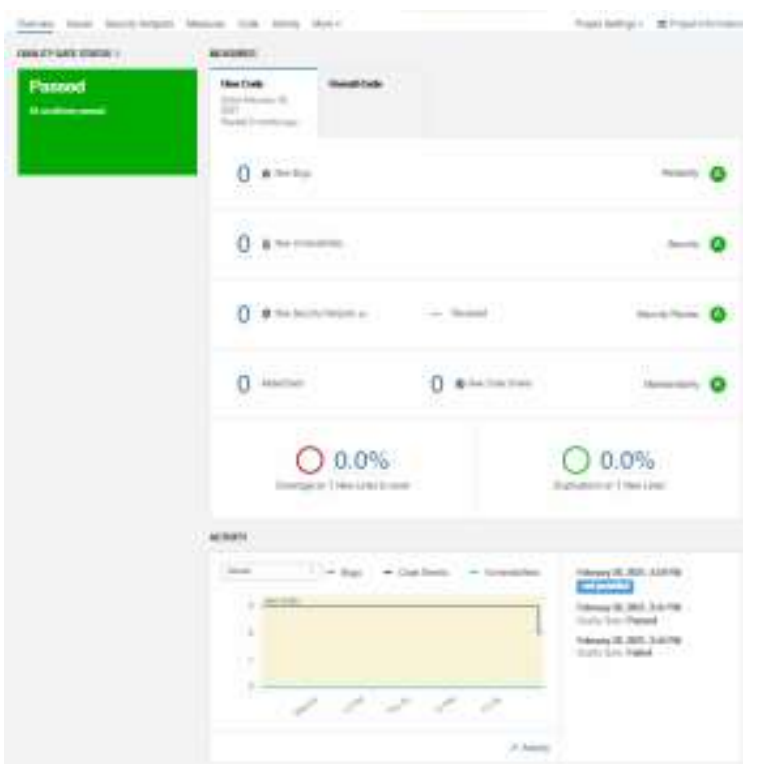

Gambar 6. Hasil Report SonarQube

\section{Hasil dan Pembahasan}

Dari penelitian yang telah dilakukan dapat diketahui bahwa pembuatan payment gateway dengan microservice dilakukan dengan membagi microservice berdasarkan bank yang terintegrasi. Dengan memanfaatkan metode Agile, setiap pembagian microservice akan dikelompokkan menjadi satu set ruang lingkup. Selanjutnya service yang telah dibagi, didaftarkan ke database agar payment gateway dapat mengenali semua microservice yang terintegrasi.

Pada setiap microservice diberikan pengamanan agar hanya payment gateway yang bisa melakukan transaksi. Selain pengamanan, setiap endpoint pada microservice didaftarkan sehingga payment gateway dapat mengenali kemana transaksi akan diteruskan.

Agar dikenali, aplikasi yang ingin menggunakan payment gateway didaftarkan ke database. IKI Modal merupakan salah satu aplikasi EDR yang terintegrasi dengan payment gateway. Gambar 7 merupakan fitur yang terdapat di aplikasi IKI Modal.

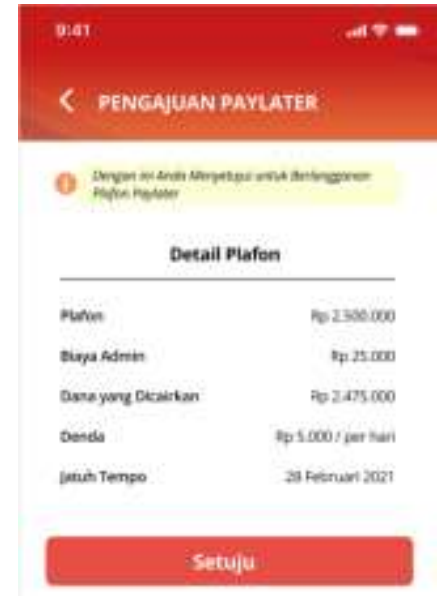

Gambar 7. IKI Modal Paylater Ajukan Talangin

Saat melakukan transaksi, sistem IKI Modal akan melakukan HTTP request ke payment gateway. Gambar 8 merupakan contoh request body dalam bentuk JSON yang dilakukan oleh sistem IKI Modal.

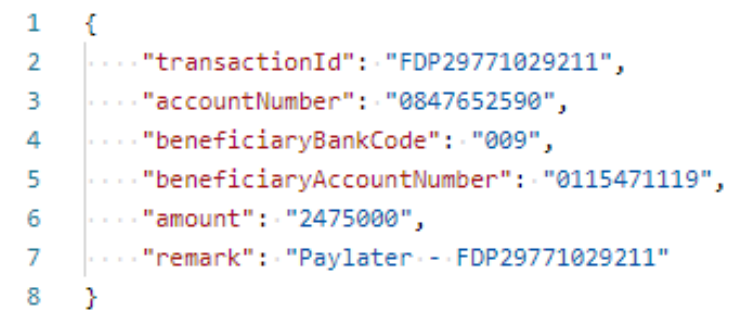

Gambar 8. Request Body Payment Gateway

Pada saat melakukan request, payment gateway akan melakukan otentikasi yang selanjut nya akan diteruskan ke service bank. Uang akan ditransfer melalui escrow account milik PT. Emporia Digital Raya ke rekening pengguna. escrow account adalah rekening bersama yang dikelola pihak ketiga (EDR). Setelah berhasil maka payment gateway akan merespon JSON seperti gambar 9. 


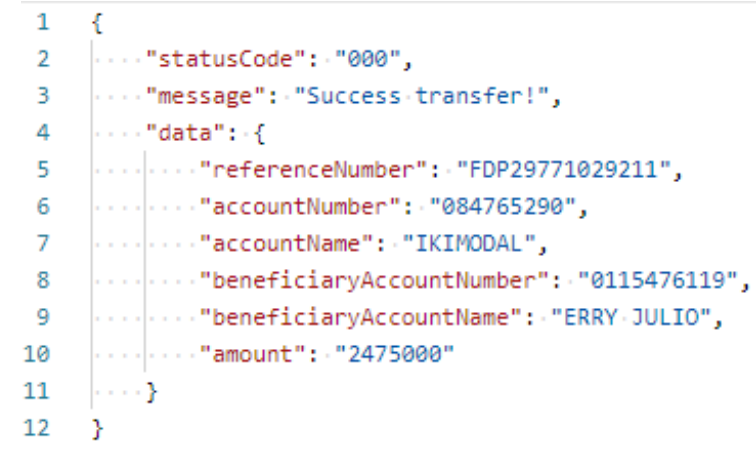

Gambar 9. Response Body Payment Gateway

Setelah payment gateway mersepon sukses ke IKI Modal, selanjutnya sistem IKI Modal akan memberikan notifikasi bahwa saldo telah masuk ke rekening pengguna seperti pada gambar 10 .

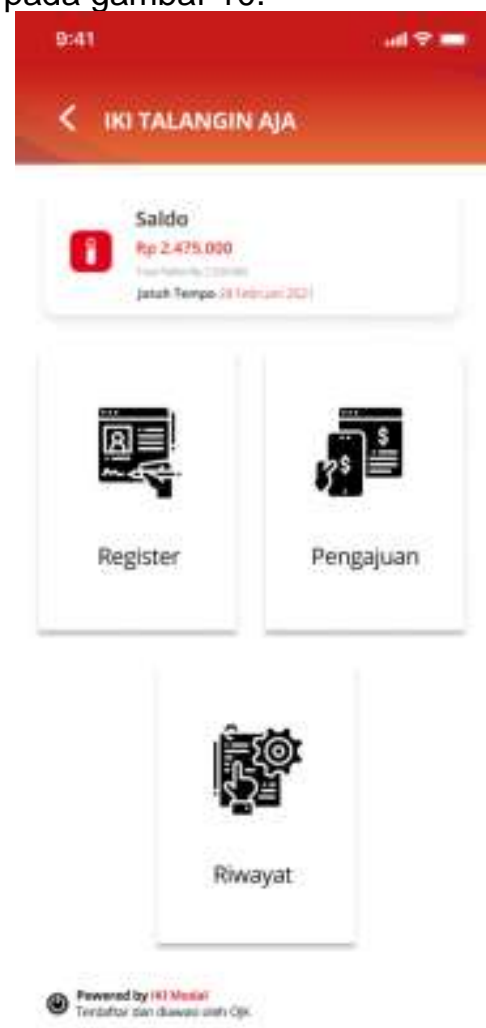

Gambar 10. Saldo IKI Talangin

\section{Kesimpulan}

Penelitian ini dilakukan dengan membangun aplikasi payment gateway menggunakan arsitektur microservice, dimana peneliti dapat memelihara aplikasi berdasarkan pembagian bank. Hal ini dapat meminimalisir kesalahan dalam melakukan pengembangan maupun pemeliharaan aplikasi. Selain itu, jika payment gateway ingin melakukan integrasi dengan bank baru maka, peneliti hanya perlu membuat microservice baru.

Berdasarkan report pengujian unit yang telah dilakukan dengan SonarQube sebagaimana telah tampilkan pada Gambar, ditemukan beberapa isu pada kode berupa kesalahan penulisan sintaks. Setelah melakukan perbaikan dan pengujian ulang berdasarkan Gambar 6, tidak ditemukan adanya bugs maupun kerentanan pada keamanan. Dengan menggunakan konsep routing membuat aplikasi sangat fleksibel dalam melakukan transaksi ke sesama bank maupun berbeda bank. Pada Gambar 9 didapatkan respon sukses dari microservice yang selanjutnya akan diteruskan ke payment gateway dan akan diteruskan lagi ke aplikasi IKI Modal. Berdasarkan cek saldo Gambar 10, dapat disimpulkan bahwa transaksi yang dilakukan telah berhasil.

Selain payment gateway arsitektur ini dapat digunakan oleh proyek yang berskala besar untuk mengurangi kompleksitas dan mempermudah pemeliharaan pada suatu aplikasi.

Saat aplikasi sudah sangat banyak transaksi diperlukan optimalisasi terhadap performa agar aplikasi tidak menunggu respon terlalu lama. Dikarenakan payment gateway berkomunikasi dengan microservice menggunakan REST API maka protokol yang digunakan adalah HTTP.

Pada penelitian yang dilakukan (Permatasari and Dhika 2018), pertukaran data dengan HTTP dapat dioptimasi dengan menggunakan protokol Message Queuing Telemetry Transportasi (MQTT). Menurut penelitian tersebut, MQTT lebih cepat 9 kali dibandingkan dengan HTTP. MQTT menggunakan pola publish atau subscribe yang dirancang terbuka, ringan, dan mudah untuk diimplementasikan. Pola publish/subscribe memiliki kelebihan yang disebut decouple, maksudnya baik pengirim maupun penerima pesan tidak berkomunikasi secara langsung. Salah satu contoh aplikasi yang mengimplementasikan MQTT adalah RabbitMQ.

Dalam pengembangan atau penelitian berikutnya diharapkan untuk menggunakan aplikasi message broker seperti RabbitMQ atau Apache Kafka.

\section{Referensi}

Adi Pranata, Beni, Astria Hijriani, and Akmal Junaidi. 2018. "Perancangan Application Programming Interface (Api) Berbasis Web Menggunakan Gaya Arsitektur Representational State Transfer (Rest) Untuk Pengembangan Sistem Informasi Administrasi Pasien Klinik Perawatan Kulit." Jurnal Komputasi 6(1): 33-42.

Aljburi, Dalya. 2016. "RoutingProtocols." : 10.13140/RG.2.1.4310.4249.

Amazon Web Services. 2017. "Microservices on AWS." AWS Whitepaper (September): 
39.

Chandra, Yuri et al. 2020. "Implementasi Arsitektur Microservice Pada Aplikasi Web Pengajaran Agama Islam Home Pesantren." 1(November): 88-97.

Chandramouli, Ramaswamy. 2019. "NIST Special Publication 800-204 - Security Strategies for Microservices-Based Application Systems." NIST Special Publication.

https://nvlpubs.nist.gov/nistpubs/SpecialP ublications/NIST.SP.800-204.pdf.

Francesco, Paolo Di, Paolo Di, Patricia Lago, and Ivano Malavolta. 2019. "Architecting with Microservices: A Systematic Mapping Study The Journal of Systems and Software Architecting with Microservices: A Systematic Mapping Study." The Journal of Systems \& Software 150(April): 77-97. https://doi.org/10.1016/j.jss.2019.01.001.

Gunawan, Rohmat, and Alam Rahmatulloh. 2019. "JSON Web Token (JWT) Untuk Authentication Pada Interoperabilitas Arsitektur Berbasis RESTful Web Service." Jurnal Edukasi dan Penelitian Informatika (JEPIN) 5(1): 74.

Jiménez, Victor, Paulo Afonso, and Gabriela Fernandes. 2020. "Using Agile Project Management in the Design and Implementation of Activity-Based Costing Systems." Sustainability (Switzerland) 12(24): 1-23.

Lakshmi, D. Rajya, and S. Suguna Mallika. 2017. "A Review on Web Application Testing and Its Current Research Directions." International Journal of Electrical and Computer Engineering 7(4): 2132-41.

Mufrizal, Rizki, and Dina Indarti. 2019. "Refactoring Arsitektur Microservice Pada Aplikasi Absensi PT. Graha Usaha Teknik." Jurnal Nasional Teknologi dan Sistem Informasi 5(1): 57-68.
Pahl, Claus, and Pooyan Jamshidi. 2020. "CLOSER 2020 - Proceedings of the 10th International Conference on Cloud Computing and Services Science." CLOSER 2020 - Proceedings of the 10th International Conference on Cloud Computing and Services Science 1(Closer): 137-46.

Permatasari, Claudia Felicia, and Harry Dhika. 2018. "Optimasi Jalur Transfer Data Dari HTTP Menjadi MQTT Pada IOT Menggunakan Cloud Services." JISA(Jurnal Informatika dan Sains) 1(2): 67-72.

Saarimaki, Nyyti, Maria Teresa Baldassarre, Valentina Lenarduzzi, and Simone Romano. 2019. "On the Accuracy of SonarQube Technical Debt Remediation Time." Proceedings - 45th Euromicro Conference on Software Engineering and Advanced Applications, SEAA 2019 (August): 317-24.

Sahoo, Pravat, Nilesh Kumar Janghel, and Debabrata Samanta. 2017. "Securing WEB API Based on Token Authentication." : 4-7.

Setya Budi, Cahyanto, and Adam Mukharil Bachtiar. 2018. "Implementasi Arsitektur Microservices Pada Backend Comrades." Program Studi Teknik Informatika, Universitas Komputer Indonesia: 1-6.

Zhao, J. T., S. Y. Jing, and L. Z. Jiang. 2018. "Management of API Gateway Based on Micro-Service Architecture." Journal of Physics: Conference Series 1087(3). 